\title{
Diagnostiske utfordringer hos en mann med subaraknoidalblødning
}

\author{
En 39 år gammel mann ble innlagt med subaraknoidalblødning. Angio- \\ grafi viste utbredt kaliberveksling i intracerebrale arterier, forenlig \\ med cerebral vaskulitt. Kontrollangiografi fire uker senere viste imid- \\ lertid at pasienten hadde en annen lidelse.
}

Se kommentar side 2492 og kunnskapsprøve på www.tidsskriftet.no/quiz

\begin{abstract}
Pasienten var en 39 år gammel mann med multippel sklerose som tidligere hadde fått immunmodulerende behandling med interferon. Ved innkomst sto han på vitamin $D$ 20000 IE/uke og kalsium 500 mg/dag som ledd $i$ en multippel sklerose-studie. Han hadde nylig vært gastro- og koloskopert grunnet gjentatte episoder med blodig avføring, men uten andre funn enn gastritt.

Innleggelseskvelden fikk han akutt innsettende, intens og pulserende bakhodepine, som i løpet av ti minutter spredte seg til begge tinninger. Smertene vedvarte, med en intensitet på mellom 9 og 10 på en visuell analog skala (VAS), og han var lyssky, kvalm og kastet opp. Han ble via legevakten innlagt i nevrologisk avdeling ved Universitetssykehuset Nord-Norge med mistanke om subaraknoidalblødning. Ved innkomst hadde han intens bakhodepine og var lyssky, men ikke nakkestiv. Nevrologisk og øvrig somatisk undersøkelse var normal. Blodprøver viste en lettgradig leukocytose, med hvite blodceller $11,4 \cdot 10^{\%} / \mathrm{l}$ og nøytrofile celler $9,0 \cdot 10 \%$ l. Andre prøver - hemoglobinnivå, trombocytter, leverenzymer og nyrefunksjonsprøver, elektrolytter, INR-nivå, cephotest, fibrinogen og D-dimer - var normale.
\end{abstract}

Med en sykehistorie med akutt sterk hodepine ledsaget av lysskyhet, kvalme og oppkast, men uten fokale nevrologiske funn ved undersøkelse, var det naturlig å sette subaraknoidalblødning øverst på listen over aktuelle differensialdiagnoser. En annen aktuell diagnose var migrene.

På mistanke om subaraknoidalblødning ble det rekvirert CT caput. På denne var det tegn til subaraknoidalt blod beliggende over konveksitetene langs gyri på begge sidene av falx cerebri. Differensialdiagnostisk kunne det dreie seg om eksudasjon av proteinrik væske. Det ble deretter utført MR cerebrum med arteriell og venøs angiografi, som viste multippel sklerose-forandringer, som ved tidligere undersøkelser, samt subaraknoidalt blod som beskrevet. Aneurismer eller karmisdannelser ble ikke påvist. I figur 1 er CT- og MR-funnene vist. Spinalvæskeanalyse 12 timer senere viste rikelig med erytrocytter, men fravær av bilirubin. Proteinverdien og leukocyttallet i spinalvæsken var lett forhøyet, henholdsvis $875 \mathrm{mg} / \mathrm{log} 6 \cdot 10^{6} / \mathrm{l}$, noe som også kunne forklares av multippel sklerose.

Sykehistorien, kliniske funn, CT- og MRbilder var altså forenlig med subaraknoidalblødning, men noe åpenbart blødningsfokus kunne ikke påvises. Den symmetriske lokaliseringen av blodet over konveksitetene på begge sider av falx cerebri var også uvanlig.

Dag 2 hadde pasienten kun lett hodepine og følte seg $i$ bedre form. I forbindelse med defekasjon fikk han tilbakefall av intens hodepine, kvalme og lysskyhet. En CT-kontroll viste uendrede funn. Ny spinalpunksjon ble utført dag 3. I tillegg til erytrocytter ble det nå også påvist bilirubin. På grunn av vedvarende blodig avføring ble det rekvirert sigmoidoskopi. Konklusjonen var proktosigmoiditt, og pasienten fikk behandling med prednisolon rektalvæske.

Vi sto her overfor en pasient med subaraknoidalblødning med atypisk lokalisering og klinisk presentasjon. Subaraknoidale blødninger ses hyppigst som følge av rumperte aneurismer eller arteriovenøse karmalformasjoner, men kan også forekomme ved sinusvenetrombose og cerebral vaskulitt.

Det ble startet utredning med henblikk på bakenforliggende systemisk vaskulitt. De vaskulitter som hyppigst affiserer sentralnervesystemet, er Behçets sykdom og polyarteritis nodosa. Også vaskulitter assosiert med antinøytrofile cytoplasmaautoantistoffer (ANCA), som Wegeners granulomatose, mikroskopisk polyangitt og Churg-Strauss syndrom, samt kryoglobulinemiassosiert vaskulitt kan en sjelden gang affisere hjernen. Det ble gjort CT thorax og CT bihuler samt abdominal angiografi - med normale funn. Undersøkelser på antimyeloperoksidase (MPO) og PR-3-ANCA var negative, det samme gjaldt kryoglobuliner. Inflammasjonsmarkører og hematologisk status var normale, uten eosinofili. Kreatininverdien var normal og urinstiks negativ. Antinukleære antistoffer (ANA), C3, C4, lupusantikoagulant var negativ, mens det var grenseverdi for antikardiolipinantistoffer. Det ble heller ikke funnet holdepunkter for systemisk lupus erythematosus, Sjögrens syndrom eller dermatomyositt. Biopsi fra tykktarm viste kronisk betennelse med fokal kryptitt uten vesentlig begercelletap, kryptabscesser, granulomer eller ulcerasjoner. Intraarteriell cerebral angiografi ble utført på dag 4 og viste utbredte områder med kaliberveksling i både fremre, midtre og bakre hjernearterie bilateralt (fig 2).

Med utgangspunkt i disse funnene ble det vurdert om det kunne foreligge en isolert cerebral vaskulitt. Ved ny gjennomgang av sykehistorien kom det frem at pasienten det siste halvåret hadde hatt flere episoder med forbigående mindre intens hodepine $\mathrm{i}$ forbindelse med seksuell aktivitet/orgasme. Det viste seg også at han tidligere hadde brukt amfetamin, at han røykte hasj regelmessig og hadde røykt hasj timen før den aktuelle hodepinen debuterte. Ved revmatologisk tilsyn ble det reist spørsmål om det kunne dreie seg om reversibelt cerebral vasokonstriksjon-syndrom. I litteraturen er det beskrevet flere former av dette syndromet under et mangfold av eponymer og navn. Ettersom sykehistorien og funnene hos pasienten var forenlig med tilstanden, valgte vi å observere pasienten under pågående behandling med nifedipin og gjorde ny cerebral angiografi fire uker senere. Denne viste komplett tilbakegang av tidligere påvist segmental vasokonstriksjon (fig 2).

\section{Diskusjon}

Reversibelt cerebral vasokonstriksjon-syndrom er en klinisk-angiografisk entitet som innbefatter akutt, intens, residiverende hodepine, eventuelt fluktuerende nevrologiske funn og reversibel segmental vasokonstriksjon som typisk affiserer flere cerebrale arterier i multiple kargebeter (1). Et potensielt forvirrende trekk ved tilstanden er ledsagende subaraknoidalblødning, som er rapportert hos $25 \%$ (1). Dette kan by på diagnostiske utfordringer, men med kjennskap til tilstandens kliniske presentasjon og angiografiske funn kan man med stor grad av sik- 

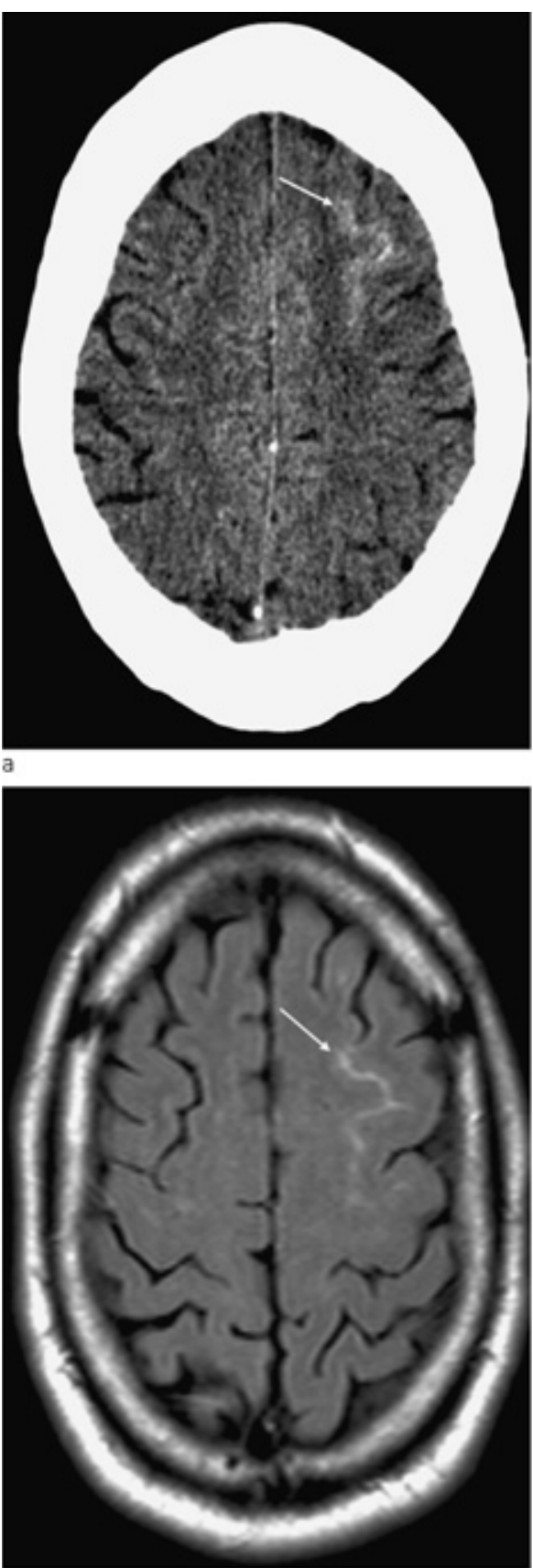

b

Figur 1 a) CT-og b) MR-snitt (aksial FLAIR) som viser utbredelse av subaraknoidalt blod mellom gyrus frontalis superior og media (piler)

kerhet stille diagnosen. Det er grunn til å tro at den forekommer hyppigere enn tidligere antatt og lett kan overses eller feildiagnostiseres.

Tilstanden ble først beskrevet av Call og medarbeidere i 1988 som «Call syndrome» eller «Call-Fleming syndrome» (2). Etter dette er flere liknende tilstander blitt beskrevet under navn som «benign angiopathy of the central nervous system» (3), «postpartum angiopathy» (4), «thunderclap headache with reversible vasospasm» (5), «migrainous vasospasm/angiitis» (6) og «drug-induced cerebral arteritis/angiopathy» (7). En av autoritetene på tilstanden, L. Calabrese, har anbefalt å samle alle disse benevnelsene under beteg- nelsen «reversibelt cerebral vasokonstriksjon-syndrom» (RCVS) (8), derfor er det denne som er benyttet i denne artikkelen.

Patogenesen er mangelfullt forstått, men en forstyrrelse $\mathrm{i}$ den cerebrale vaskulære kontrollen ser ut til å spille en sentral rolle. Syndromet rammer oftest unge voksne og opptrer tre ganger så hyppig hos kvinner som hos menn (1). Tilstanden kan oppstå spontant, men er vanligvis assosiert med en utløsende faktor, ofte reseptfrie sympatomimetika slik som nesespray eller andre vasoaktive substanser som pseudoefedrin, ergotderivater, kokain og medikamenter som modulerer det dopaminerge og seratonerge systemet. Cannabis kan også forårsake cerebral vasospasme (8).

Ikke-farmakologiske faktorer inkluderer fødsel, porfyri, feokromocytom, carotisendarterektomi og intravenøs immunoglobulinbehandling (1). Tilstanden er også beskrevet ved koital hodepine (9).

Hodepinen er vanligvis lokalisert oksipitalt eller over vertex. Den ofte hyperakutte og kraftige karakteren (thunderclap headache) reiser ofte mistanke om subaraknoidalblødning. Subaraknoidalblødninger ved denne tilstanden er typisk lokalisert over den superolaterale del av hjerneoverflaten, en uvanlig lokalisering for subaraknoidalblødning forårsaket av aneurismeruptur. Blødningene er oftest minimale eller middels store og er ikke årsak til den utbredte segmentale vasokonstriksjonen. Dette i motsetning til aneurismeblødninger, der vasokonstriksjonen er lokalisert i umiddelbar nærhet til aneurismet (1). Hodepinen svinger i intensitet, forverres av fysisk aktivitet og avtar gradvis over dager til uker. Synsforstyrrelser er vanlig i forløpet og tilskrives vasogent ødem i oksipitallappene, tilsvarende det man ser ved posterior reversibel encefalopatisyndrom (10). Liknende og forbigående nevrologiske utfall ses også ved migrene og transitorisk iskemisk anfall (TIA), selv om hodepine er uvanlig ved sistnevnte tilstand.

Et absolutt kriterium for å stille diagnosen er angiografisk påvisning av reversibel segmental vasokonstriksjon i cerebrale arterier som avgår fra circulus Willisi og deres grener. De poststenotiske segmentene kan være dilaterte. I de fleste tilfellene er både carotisog vertebro-basilaris-kretsløpet affisert. Forandringene kan noen ganger være beskjedne og vanskelig å avdekke på MR- og CTangiogrammer. Intraarteriell cerebral angiografi er derfor gullstandarden i diagnostikken, men bør forbeholdes pasienter med subaraknoidalblødning eller nevrologiske utfall der man frykter utvikling av cerebralt infarkt. Angiografifunnene kan likne dem man ser ved cerebral vaskulitt. Ved cerebral vaskulitt utvikles hodepinen over lengre tid, er ofte ledsaget av redusert hukommelse, kramper og påvirket allmenntilstand, og vanligvis påvises det cerebrale infarktforandringer.

Pasienter med reversibelt cerebral vaso-

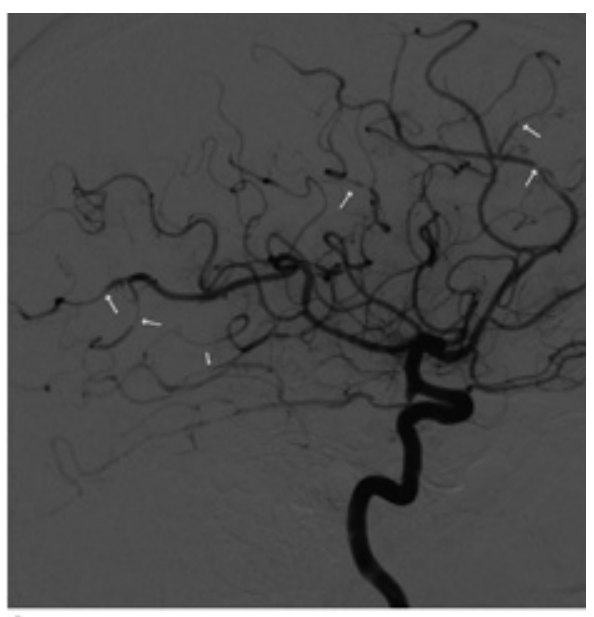

a

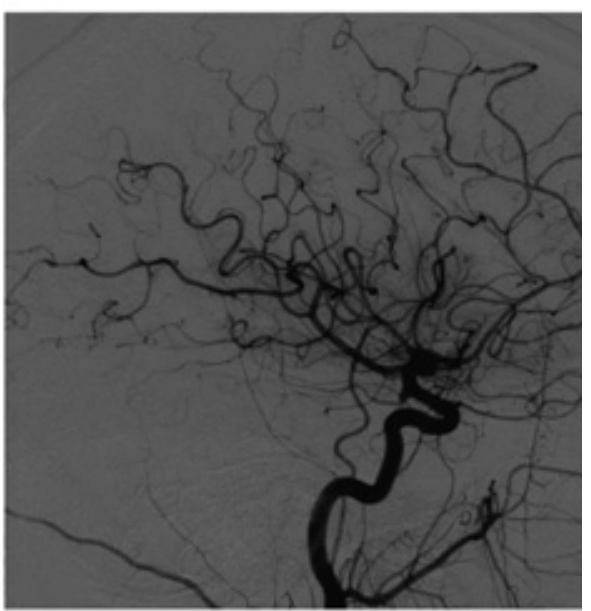

Figur 2 Intraarteriell cerebral angiografi med a) fremstilling av hjernearteriene på høyre side ved innkomst og bl ved kontroll fire uker senere. Pilene viser områder med segmental vasokonstriksjon

konstriksjon-syndrom er i relativt god allmenntilstand, til tross for utbredte angiografiske forandringer. Fravær av iskemiske lesjoner, negative blodprøver og eventuell påvisning av en utløsende årsak er med på å skille de to tilstandene fra hverandre. I tillegg vil spinalvæskeanalyse som regel være normal, i motsetning til ved cerebral vaskulitt, der man finner lettgradig pleocytose og økte proteinverdier i $80-90 \%$ av tilfellene (11). Det anbefales kontrollangiografi etter 3-6 uker. Hvis man på denne finner normalisering av tidligere funn, er diagnosen bekreftet.

Prognosen er god, ettersom fullstendig remisjon av symptomene er hovedregelen ( $>95 \%$ av rapporterte tilfeller). Tilbakefall av tilstanden er heller aldri blitt rapportert (1). Den kan imidlertid ha et forlenget forløp (8). Seponering av mistenkte vasoaktive substanser er av største viktighet, på linje med nøye blodtrykkskontroll. Vanligvis kan hodepinen kuperes med paracetamol. I tillegg anbefales det bruk av en kalsiumantagonist (nimodipin eller nifedipin) for å påskynde reversering av vasokonstriksjonen, ettersom hjerneinfarkt er rapportert som 
komplikasjon til tilstanden. Andre behandlinger som har vært benyttet er korte steroidkurer. Magnesiumsulfat har vært brukt i en del postpartumtilfeller (3).

Pasienten har gitt samtykke til at artikkelen blir publisert.

\section{Mikal Tønsaas \\ mikal@stortorget4.no \\ Legekontoret Stortorget \\ Stortorget 4 \\ 9008 Tromsø}

Stein Harald Johnsen

Nevrologisk avdeling

Marit Seip

Revmatologisk avdeling

Petter Eldevik

Radiologisk avdeling

Universitetssykehuset Nord-Norge
Oppgitte interessekonflikter: Ingen

\section{Litteratur}

1. Moustafa RR, Allen CM, Baron JC. Call-Fleming syndrome associated with subarachnoid haemorrhage: three new cases. J Neurol Neurosurg Psychiatry 2008; 79: 602-5.

2. Call GK, Fleming MC, Sealfon $S$ et al. Reversible cerebral segmental vasoconstriction. Stroke 1988: 19: 1159-70.

3. Moskowitz SI, Calabrese LH, Weil RJ. Benign angiopathy of the central nervous system presenting with intracerebral hemorrhage. Surg Neurol 2007; 67: 522-7

4. Calado S, Viana-Baptista M. Benign cerebral angiopathy; postpartum cerebral angiopathy: characteristics and treatment. Curr Treat Options Cardiovasc Med 2006; 8: 201-12.

5. Dodick DW, Brown RD jr., Britton JW et al. Nonaneurysmal thunderclap headache with diffuse, multifocal, segmental, and reversible vasospasm. Cephalalgia 1999; 19: 118-23.

6. Jackson M, Lennox G, Jaspan T et al. Migraine angiitis precipitated by sex headache and leading to watershed infarction. Cephalalgia 1993; 13 : 427-30.
7. Gautier JC. Segmental cerebral angiopathy of drug addicts. Physiopathological significance. Possible role of spasms. Bull Acad Natl Med 1988; 172: 87-93.

8. Calabrese LH, Dodick DW, Schwedt TJ et al. Reversible cerebral vasoconstriction syndromes. Ann Intern Med 2007; 146: 34-44.

9. Keyrouz S, Dhar R, Axelrod Y. Call-Fleming syndrome and orgasmic cephalgia. Headache 2008; 48: 967-71

10. Arntzen KA, Albretsen C, Bajic R. En eldre kvinne med akutte pareser og synstap. Tidsskr Nor Lege foren 2007; 127: 593-6.

11. Koopman K, Uyttenboogaart M, Luijckx GJ et al. Pitfalls in the diagnosis of reversible cerebral vasoconstriction syndrome and primary angiitis of the central nervous system. Eur J Neurol 2007; 14: $1085-7$.

Manuskriptet ble mottatt 12.5. 2009 og godkjent 2.7. 2009. Medisinsk redaktør Odd Terje Brustugun.

\section{Kun en skygge av virkeligheten}

Tønsaas og medarbeidere presenter sykehistorien til en 39 år gammel mann som brått utviklet en intens hodepine. Nevroradiologisk undersøkelse med CT cerebrum viste blod beliggende subaraknoidalt over hjernekonveksitetene. Ved intraarteriell cerebral angiografi fire dager senere fant man intet aneurisme, som primært mistenkt, men betydelige patologiske forandringer med segmentale forsnevringer på alle store hjernearterier. Fire uker senere var pasienten uten hodepine, og ny cerebral angiografi viste komplett normalisering.

Utviklingen innen nevroradiologien har revolusjonert mulighetene for presis diagnostikk og behandling av mange hjernesykdommer. CT- og MR-angiografi har langt på vei erstattet intraarteriell angiografi for diagnostisk bildefremstilling av hjernens arterier. Ikke-invasiv påvisning av arteriell okklusjon ved akutt hjerneinfarkt og aneurisme ved subaraknoidalblødning tar få minutter og gir klinikeren avgjørende informasjon for valg av behandling i akuttfasen. Trass i denne teknologiske suksessen er det viktig å huske at bildedannende metoder kun gir oss «en skygge av virkeligheten» - ikke minst gjelder dette angiografi. Dette er en teknikk som avbilder en kontrastsøyle eller blodstrømmen i et kar, den gir begrenset informasjon om bakenforliggende patofysiologi eller patologisk anatomi. Radiologisk påvist forsnevring på en cerebral arterie kan ha en rekke forklaringer, alt fra reaktiv vasospasme til arteriosklerose, strålingssekvele, infeksjon, karveggsinflammasjon, fibromuskulær dysplasi, neoplasme eller radiologisk artefakt.
Tradisjonelt er et angiografisk funn av utbredte segmentale forsnevringer på en eller flere av hjernens arterier blitt tolket synonymt med cerebral arteritt. Intraarteriell cerebral angiografi er blitt sett på som selve gullstandarden for denne diagnosen. Både primær og sekundær (til ekstrakranial revmatisk sykdom) cerebral arteritt er en ofte progredierende og mulig fatal tilstand som skal behandles med høydosert kortikosteroid og gjerne et cytostatikum (cyklofosfamid). Behandlingen går over måneder til flere år og har en rekke potensielt alvorlige bivirkninger, som osteoporose og diabetes mellitus, og medfører fare for maskering av infeksjon. Dessuten fremmer kortikosteroider arteriosklerose.

Nyere studier sannsynliggjør at cerebral arteritt nok er enda sjeldnere forekommende enn tidligere antatt (1), og at selv gullstandarden intraarteriell cerebral angiografi har for liten sensitivitet og spesifisitet til å stille diagnosen med rimelig grad av presisjon (2). Mange tilfeller av cerebral arteriosklerose og ikke minst av reversibelt cerebral vasokontriksjon-syndrom (3) har vært tolket som cerebral arteritt. Forståelig nok vil en angiografisk normalisering uker til måneder etter oppstart av immunsupprimerende medikasjon lett bli oppfattet som utrykk for positiv behandlingseffekt og gi støtte for videre behandling. Slik angiografisk normalisering kan derimot være helt uavhengig av behandlingen og heller representere reversibelt cerebral vasokonstriksjon-syndrom eller radiologiske artefakter ved primærundersøkelsen. Med tanke på de mange differensial- diagnosene og farene ved tung og langvarig immunsuppressiv behandling bør hjernebiopsi alltid utføres før oppstart av medikamentell behandling, i alle fall på indikasjonen primær cerebral arteritt.

En angiografisk fremstilling av en arterie er kun et øyeblikksbilde. Et minutt, en time eller en uke senere kan arterien ha en helt annen konfigurasjon. Historien om «oppdagelsen» av reversibelt cerebral vasokonstriksjon-syndrom gir oss nok en gang en påminnelse om at «sannheter» $i$ medisinen er ferskvare og at det viktigste for en lege er å se til at den medisinske behandlingen ikke er mer til skade enn til gagn for pasienten.

\section{Christian Lund}

christian.lund@rikshospitalet.no

Nevrologisk avdeling

Oslo universitetssykehus, Rikshospitalet

0027 Oslo

\section{Oppgitte interessekonflikter: Ingen}

\section{Litteratur}

1. Birnbaum J, Hellmann DB. Primary angiitis of the central nervous system. Arch Neurol 2009; 66: $704-9$.

2. Kadkhodayan Y, Alreshaid A, Moran CJ et al. Primary angiitis of the central nervous system at conventional angiography. Radiology 2004; 233: 878-82.

3. Ducros A, Bousser MG. Reversible cerebral vasoconstriction syndrome. Pract Neurol 2009; 9: 256-67.

Manuskriptet ble mottatt 30.9. 2009 og godkjent 15.10. 2009. Medisinsk redaktør Odd Terje Brustugun. 